\title{
The Need for Integrating Emotional Intelligence as an Essential Skill for Graduates with Special Reference to Employability of Engineering Graduates
}

\author{
Vani. M, H Sankaran, S. Praveen Kumar
}

\begin{abstract}
Emotional intelligence has now become one of the preeminent qualifiers for professional success. A graduate who is selected for a job aspires to rise to greater levels; contribute towards sustainable growth of the organisation, while a bad recruit paves the way towards expenditure and unexpected loss to an organization. Many leading technology driven organisations like Google count more on Emotional Intelligence as required skill as against the academic excellence or school from where the student has graduated from.

This paper focuses on empirical comparison of emotional intelligence of Graduates as against their capacity to handle their first job, the research was conducted on 200 engineering graduates who have recently taken up their first job in the corporate world. The data has been collected using a questionnaire method each consisting of questions which are directly aimed to analyse the preparedness to perform in their first job. The analysis includes psychological state and behavioural analysis of these Graduates.Dimensions like Self-awareness, Self- management, Self-discipline, social -awareness, effective communication and Attitude have been taken into consideration for the analysis.

The findings and suggestions in this paper can be recommended to educational institutions in preparing their students with equal importance to subject knowledge. Results show that emotional skill is the key to handle practical situations and stress with the right attitude in their first job, this skill can help them become better contributors at work in the long run.
\end{abstract}

Keywords: Emotional Intelligence, Intelligence Quotient, Self-awareness, Self- management, Self- discipline, social -awareness, effective communication and Team work

\section{INTRODUCTION}

Post recruitment many organisations are hit hard by the tardy behaviour among youngsters which spikes through the peer groups and has set a procrastinating approach amongst new recruitsthat hampers the growth and culture of an organisation.Many technology driven companies'campaign for essential technical skills/knowledge as required by job description in their organisation, in recent times

\section{Revised Manuscript Received on July 22, 2019.}

Vani M, MBA, Bharath Institute of Higher Education and Research, Tambaram, India.

H Sankaran , MBA, Meenakshi College of Management Studies, Kodambakkam, India.

S Praveen Kumar, MBA, Bharath Institute of Higher Education and Research, Tambaram, India organizations affirm Emotional stability of the recruit as one of the vital requirements, which has been neglected for many years now. Social media presence is tested as one such tool to see how the individual reacts to posts and the kind of engagement the individual reacts to, especially to study the attitude of the candidate.

\section{LITERATURE REVIEW}

Research has shown that top managers in various national and multinational organizations have been successful due to high level of emotional intelligence they practice and possess.Emotional Intelligence has been defined as "a set of skills that enables us to make our way in a complex world the personal, social and survival aspects of overall intelligence, the elusive common sense and sensitivity that are essential to effective daily functioning" (Stein and Book 2011, p. 14).

Many higher education institutions are focusing on offering students hard and soft skills training to enhance their core competencies, technical knowledge and communication skills to help them secure a fair chance in the campus drives conducted by them and to prepare them to participate in a "global knowledge-based economy" (Chan, Brown and Ludlow, 2014, p. 2).

According to McArthur 2011 (p. 737) the recent "trend" among higher education institutions is to "redesign" and "re-brand" themselves in order to meet the demands of governing and authorising bodies. Often, the transition phase from higher education to work life does not follow a clear and welldefined path, often resulting in it being a challenging and problematic time for graduates as they often feel illprepared for the challenges and reality of employment (Dahlgren, Solbrekke, Karseth and Nyström 2014 in Billett, Harteis and Gruber)

EI is believed to create awareness regarding self, illuminates the essence for monitoring one's emotions and highlights the need of developing social skills. When a student strengthens these qualities it brings about a positive change effectively which helps the new recruits to adapt to changing situations. Students with bookish knowledge may not necessarily possessEI and may therefore find it difficult to learn from their mistakes. Students who are strong in IQ and technical skills can easily understand work but may not possess an analytical

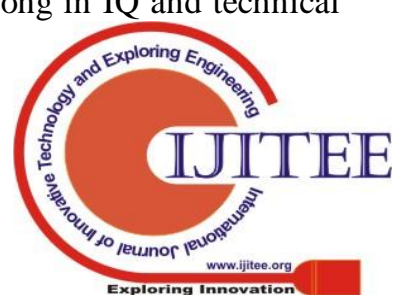


brain. Research has proved that emotional intelligence is a positive differentiator of job performance, especially for leaders. Emotional intelligence is often misconceived as being good to all, on the contrary people with strong EI are assertive and are ardent learners. Human beings have the capacity to shape our thought process and behaviour through cognitive practices EI can be imbibed into young minds through training, coaching and mentoring.

\section{COACHING AND MENTORING}

\section{A. Coaching}

Coaching is generally offered to suit an intended objective which are future focussed. Coaching interventions are generally sponsored by organisations and are intended for senior level leaders. The purpose of coaching generally helps the coached to gain clarity in many areas which includes,clarity in thinking process, clarity in intrapersonal traits of self, ability to curb negative emotions, ability to handle anger, ability to handle uncerternity which are acquired over a period of time after many sessions over a long time period of time. The role of a coach is beyond a trainer, coaching is process of sefl-discovery and motivation toward progress.

It is believed that the most efficientapproach to deliver emotional intelligence training is via coaching.Research shows that it is possible to enhance EI by habituating empirical and observational practices. A well-developed coaching intervention can help improve interpersonal skills in a short term. Many certified coaches run tested sessions for corporates employees, on understanding the basic training offered many employees practice self-coaching. Similarly session on simulations are highly recommended to help employees solve problems, manage stress, make decisions and interact with their team.

\section{B. Mentoring}

A Mentor student relationship is the most valued in all colleges and universities, a mentor helps the student in all facets of their academic life. They guide them through in developing their careers goals, interpersonal relationships, manage time, mange cultural differences and gender issues etc..

A good mentor should be accessible and friendly, great achievers have been mentored by great Mentors, Graduates need a good mentor for achieving greater goals.

\section{ONLINE TRAINING SESSIONS}

A periodical online session can also help improve Emotional Intelligence among employees. A proper schedule of the above activities can help a student's improve his/her EI, because to change the way the brain reacts needs time and practice.

\section{RECORDING THE IMPACT}

Using technology, valid assessments have to conduct to measure the outcomes of such trainings and all data has to be documented for future study. Recommendations based on the data and the advice from the coach can help improve EI of the individual.

\section{RESEARCH METHODOLOGY}

The Research Methodology adapted for this paper included both primary and secondary data. Information was all collected from various sources as secondary data from Libraries, Journals and Articles from Internet and via google scholar. The primary data collected from fresh recruits from various colleges were collected to check the readiness of the graduate to start job. The questionnaire focused on dimensions like Self-awareness, Self- management, Self-discipline, social -awareness, effective communication and Attitude.

The questionnaire was distributed to 250 students and 200 completed forms were received. Totally

136 male and 64 female candidates participated in the survey.

Table: 1 Percentage of new recruits -male and female candidates

\begin{tabular}{|l|c|c|}
\hline & Frequency & Percent \\
\hline Male & 136 & 68.0 \\
\hline Female & 64 & 32.0 \\
\hline Total & 200 & 100.0 \\
\hline
\end{tabular}

Table: 2 Readiness to work by fresher -Graduates in their first Job

\begin{tabular}{|l|l|r|r|r|r|r|}
\hline Self-Awareness & Within Groups & 73.796 & 184 & 9.049 & & \\
\cline { 2 - 7 } & Total & 86.286 & 198 & & & \\
\hline \multirow{3}{*}{$\begin{array}{l}\text { Effective } \\
\text { Communication }\end{array}$} & Between Groups & 14.186 & 17 & 31.593 & 6.104 & .002 \\
\cline { 2 - 7 } & Within Groups & 89.289 & 181 & 7.921 & & \\
\cline { 2 - 8 } & Total & 103.475 & 198 & & & \\
\hline \multirow{4}{*}{ Self-Confidence } & Between Groups & 15.512 & 14 & 26.256 & 5.278 & .010 \\
\cline { 2 - 8 } & Within Groups & 74.108 & 184 & 10.644 & & \\
\cline { 2 - 8 } & Total & 89.620 & 198 & & & \\
\hline \multirow{3}{*}{$\begin{array}{l}\text { Intelligence } \\
\text { Attitude }\end{array}$} & Between Groups & 13.211 & 14 & 31.605 & 6.317 & .001 \\
\cline { 2 - 7 } & Within Groups & 82.264 & 184 & 7.321 & & \\
\cline { 2 - 7 } & Total & 95.475 & 198 & & & \\
\hline & Between Groups & 19.122 & 14 & 39.561 & 6.878 & .002 \\
\cline { 2 - 7 } & Within Groups & 86.538 & 184 & 7.747 & & \\
\cline { 2 - 7 } & Total & 105.66 & 198 & & & \\
\hline
\end{tabular}

From the above table it is evident that Emotional Intelligence has a significant influence on the candidate's readiness to start work in an Organisation.

The above table shows that the mean values for Emotional intelligence are highest ( $\mathrm{F}$ value $6.317, \mathrm{P}$ value $<0.001 * *)$, Effective communication (F value 6.104, $\mathrm{P}$ value $<0.001 * *$ ) and Attitude ( $\mathrm{F}$ value $6.878, \mathrm{P}$ value $<0.001 * *$ ) respectively. 


\section{CONCLUSION}

Emotional intelligence as a skill does not apply to domains like human resources management or Psychology alone, it helps Managers across all domains especially to acquire top talent for the organisation. Research has proved that highly emotionally intelligent people are lifelong learners, who show consistency in growth, evolve as better being who are socially adaptable and are always open to new ideas. These qualities prepare them to learn from others. Higher education centres across the country should necessarily imbibe these qualities into the youngster who are the future creators and help them develop these impeccable qualities to help them grow and evolve as responsible human being who can be idolized.

The concept of graduate attributes which Barrie 2009 states which are: (i) the important elements that students should learn, (ii) learning outcomes of a university education, (iii) graduates as contributors to society both as citizens and as workers and, (iv) graduates who will act as agents of social change in a dynamic way, have to be implemented $t$ see emotionally strong engineers for tomorrow.

Stein says emotional intelligence training can improve leadership, team cohesiveness, productivity, employee and management engagement, hiring decisions, and work culture.

\section{REFERENCES}

[1] 1. Baker, K., Pryor, M. and Perkins, J. (nd) Achieving graduate attributes: making the implicit explicit (Retrieved 7/5/15 from http://www.enhancementthemes.ac.uk

[2] 2. Bar-On, R. (2006), The Bar-On Model of emotional-social intelligence (esi), Psicothema, 18, supl, 13-25)

[3] 3. Barrie S.C. (2009) Understanding what we mean by the generic attributes of graduates Australia: Institute for Teaching and Learning University of Sydney (Retrieved 28 August 2015 from http://www.itl.usyd.edu.au/GraduateAttributes/barriepaper.pdf

[4] 4. Bradberry, T. and Greaves, J. (2009), Emotional Intelligence 2.0, CA: TalentSmart

[5] 5. Caruso, D.R. (2008) Emotions and the Ability Model of Emotional Intelligence in Emmerling,

[6] 6. R.J., Shanwal, V.K. and Mandal, M.K. (eds), Emotional Intelligence Theoretical and Cultural Perspectives, New York: Nova Science Publishers Inc.

[7] 7. Dr. Chandra Mohan, A and Prasad, B. V. S, "Emotional Intelligence and Self Motivational Factors for Managerial Effectiveness in the Corporate World", NATIONAL MONTHLY REFEREED JOURNAL OF RESEARCH IN COMMERCE \& MANAGEMENT, VOLUME NO.1, ISSUE NO.11

[8] 8. Hassan Jorfi, "The impact of emotional intelligence on communication effectiveness: Focus on strategic alignment", African Journal of Marketing Management, Vol. 6(5), pp. 82-87, October, 2014.

[9] 9. M.Suvarchala Rani, "Emotional Intelligence - A Model for Effective Leadership, Competency and Career Growth", Indian Journal of Science and Technology, Vol 8 (S4), 240-246, February 2015

10. Vladimir, "Project Managers Emotional Intelligence - A Ticket to Success", Journal in Procedia - Social and Behavioral Sciences,74 ,274-284, 2013.

\section{AUTHORS PROFILE}

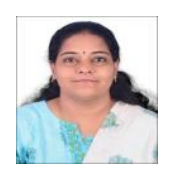

Vani. M, Research Scholar, Bharath Institute of Higher Education and Research, India

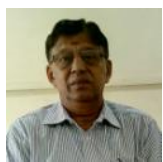

Dr. Dr.H. Sankaran, Principal, Meenakshi College of Management studies, India

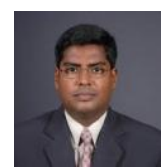

S. Praveen Kumar, Director - MBA at Bharath Institute of Higher Education and Research, India 